"(C) 2015 IEEE. Personal use of this material is permitted. Permission from IEEE must be obtained for all other uses, in any current or future media, including reprinting/republishing this material for advertising or promotional purposes, creating new collective works, for resale or redistribution to servers or lists, or reuse of any copyrighted component of this work in other works." 


\title{
Business Case Control in Project Portfolios - An Empirical Investigation of Performance Consequences and Moderating Effects
}

Keywords: Project Management, Project Portfolio Management, Business Case Control

Julian Kopmann, ${ }^{*}$ Alexander Kock**, Catherine P Killen ***, and Hans Georg Gemuenden*

* Technical University of Berlin (TU-Berlin), Institut für Technologie und Management (ITM)

** Technical University of Darmstadt, Department of Law and Economics, kock@tim.tudarmstadt.de

*** University of Technology Sydney, School of Systems, Management and Leadership, Faculty of Engineering and IT

Citation: Kopmann J, Kock A, Killen C P and Gemuenden H G, (2015) "Business Case Control in Project Portfolios - An Empirical Investigation of Performance Consequences and Moderating Effects", IEEE Transactions on Engineering Management, Vol 62, Issue 4, pages $529-543$.

\begin{abstract}
Practitioners place strong emphasis on business cases with the expectation that using business cases to inform and drive investment decisions will assist in creating value from those investments. Maximizing the value generated by project investments is a central aim of project portfolio management, and the business case provides the underlying rationale for the evaluation of the value created in each project. However, research regarding the use of business cases at a project portfolio level is scarce and there is little guidance for portfolio managers on when and how to control business cases. We identify three elements of business case control at the portfolio level - the initial review, the ongoing monitoring during project execution, and the post-project tracking until the business case is realized - and investigate the relationship between business case control and project portfolio success. Furthermore, we analyze enablers and contingencies for the application of business case control. Based on a cross-industry sample of 183 firms we find that business case control is positively related to project portfolio success. Accountability for business case realization and corresponding incentive systems increase this positive effect. Finally, we show that portfolio complexity also positively moderates the relationship.
\end{abstract}




\section{INTRODUCTION}

Practitioner and professional organization literature places strong emphasis on business cases with the expectation that the use of business cases to inform investment decisions and to guide project managers will produce better results. A common lament in the literature is that, too often, project management focuses on the technical aspects or on cost and time restrictions rather than on the achievement of the desired benefits from project efforts [1,2]. Despite the attention in the literature, little empirical research explores benefits realization management. In particular, there is a lack of quantitative studies that investigate the application of business cases for projects and the corresponding control mechanisms. So far, there is no evidence to support common claims that benefits management practices are key success factors for project and project portfolio success [3].

The business case for a project (referred to in this paper as the 'project business case' or simply the 'business case') performs three roles: it describes why and how the execution of a project can be beneficial for an organization, it forms the underlying rationale for an organization to invest in a project, and it sets the general conditions for the project scope [4, 5]. Thus, the business case not only provides directions for the management of projects but also supports decision making on a project portfolio level. Such decisions often involve the allocation of limited resources through holistic analysis of all projects (new proposals and ongoing projects), with the aim of maximizing the value of the project portfolio $[6,7]$. The current study takes a project portfolio perspective on business cases.

There is a substantial body of research on project portfolio selection processes [7, 8, 9]. Empirical studies have shown that information quality is a linchpin of project portfolio management success $[10,11,12]$. However, the quality of the information relevant for portfolio selection is constrained by the quality of the information available from the business cases provided for each project. Thus, the way business cases are considered and managed at 
the project portfolio level might be highly relevant for both project and project portfolio success and deserves research attention. However, the literature on business cases also highlights a range of issues regarding the application of business cases. The obligation to present a business case may come along with negative side effects such as self-deception, creative calculations of assumed profits, over-reliance on unrealistic assumptions, strategic misrepresentation and, in some extreme cases, even fraud $[4,13,14,15,16]$. It follows that using business cases might not be universally beneficial, and there is a lack of understanding regarding its impact and context.

The objective of this study is to better understand the portfolio-level management of project business cases and to provide guidance for managers on the aspects that influence outcomes. We aim to identify the impact of portfolio-level control and monitoring mechanisms for project business cases (referred to as business case control) on portfolio performance. Considering the possible negative side effects that stem mostly from the misconduct of the main stakeholders, we also explore managerial activities that complement and support business case control (enablers). Finally, we analyze situational factors beyond managerial control (contingencies) that may moderate the performance effect.

Consequently, the following research questions guide this study in addressing the existence, effectiveness, and context of business case control: How can business case control at the project portfolio management level be defined and measured? What is the performance effect of business case control at the project portfolio management level? Which enablers and contingencies affect the relationship between business case control and project portfolio success?

We empirically address these questions using an analysis of a cross-industry sample of 183 firms with two informants. The study contributes to the literature on project and project portfolio management by conceptually developing and empirically validating a multidimensional construct called business case control. We demonstrate its relevance by 
showing the positive impact of business case control on project portfolio success. Furthermore, we identify accountability for business cases and portfolio-based incentives as enablers of this relationship, and reveal the moderating impact of portfolio complexity.

\section{CONCEPTUAL FRAMEWORK AND HYPOTHESES}

\section{A. Business Case}

The business case forms the raison d'être for any project [2]. It demonstrates the advantages of organizational investment in a project and illustrates how the project aims to create value [3]. Although the term 'business case' is in common use commercially, there is no accepted definition of the term for research purposes.

Professional organizations and practitioner-oriented literature provide a wide range of business case definitions. Table I summarizes the definitions offered by the main project management institutions. These definitions reflect varying perspectives and levels of detail, but are consistent regarding the general scope of the business case and in recommending the use of the business case throughout the project's life-cycle. The definitions derive from different perspectives; for example from a program or portfolio management perspective the definitions from the Project Management Institute refer to broad organizational objectives, including intangible benefits $[17,18]$. The definitions from a project management perspective focus more on investment and project justification, and emphasize that a business case provides guidance for the project management team with regard to what is required from other stakeholders and what is expected to be delivered from a project [5]. Drawing upon these definitions, for the purposes of this study from a portfolio perspective, we characterize a project business case as follows:

A project business case is a document that provides the necessary information to enable management to make decisions about project prioritization and funding. It contains estimates of the benefits, timescales, resource requirements (including costs), and risks of a project. 


\section{TABLE I}

\section{DEFINITIONS OF BUSINESS CASES}

Institution | Source | Definition Project management Institute

Project management body of knowledge: "The business case or similar document provides the necessary information from a business standpoint to determine whether or not the project is worth the required investment. [...] In the case of multi-phase projects, the business case may be periodically reviewed to ensure that the project is on track to deliver the business benefits. "[19]

Standard of program management: "The business case may include details about problems or opportunities; business and operations impact; cost benefit analysis; alternative solutions; financial analysis; intrinsic and extrinsic benefits; market demands or barriers; potential profit; social need; environmental influence; legal implication; risk; time to market; constraints and the extent to which the program aligns with the organizations strategic objectives. " [17]

Standard for portfolio management 3rd Edition: "During the optimization process, component proposals provide initial assessment of expected business value and the (often intangible) contributions to organizational objectives." [18]

\section{International project management association}

Competence Baseline: "The goal of a project is to produce the deliverables defined in the business case. [...] On a tactical level the business and the legal context is linked to a project or programme through the business case. The business case states what is expected from the programme or project in terms of cost, acceptable risks and revenues, the functionality required of the results, the time-frame and resources required." [5]

\section{Office of Government Commerce}

Management of Value / Prince2: "The justification for an organizational activity (strategic, programme, project, operational) which typically contains costs, benefits, risks and timescales and against which continuing viability is tested" [20]

\section{Global Alliance for Project Performance Standards}

Project Manager Standards: “The business case should include expected benefits and the associated financial considerations, risks, and costs. [...] Complex business cases may require independent reviews. ” [21]

Some of the definitions in Table I highlight that a business case needs to be reviewed periodically and that independent reviews may be required. In the same vein, Ward et al. describe additional functions of the business case such as enabling the management to set priorities for resource allocation and providing a basis for reviewing whether a business case has been realized [4]. These considerations suggest a higher-level organizational function, such as project portfolio management, where funding decisions are made and the project portfolio is administered [22]. The business case is expected to provide essential information for the decisions on the portfolio level. At that level, the aim is not to maximize the benefits of a single project, but rather to maximize the value of the entirety of the investment in 
projects, namely project portfolio success. Hence, we consider the project portfolio management literature to establish an understanding of the relevant management system.

\section{B. Project Portfolio Management and Project Portfolio Success}

A portfolio is a group of projects that are carried out and managed within an organization [7] and compete for a shared pool of resources [7]. Cooper et al. [6] summarizes the purpose of project portfolio management as "doing the right things" and contrasts it with project management that is about "doing things right". According to their initial studies, the right projects are the ones that provide maximum value, achieve a balance, and align with strategy. Since then, Cooper and other researchers have developed a more comprehensive understanding of project portfolio success $[8,23,24,25,26,27,28,29,30,31]$. The study reported in this paper builds on recent quantitative research that distinguishes the following five dimensions of project portfolio success [10, 12, 32, 33, 34].

Projects are the main vehicles for the implementation of corporate strategies in many organizations $[11,27,35]$. Hence, the first of the five dimensions of project portfolio success is the strategy implementation success of a project portfolio [23]. The second, future preparedness, reflects the long-term perspective on portfolio success and describes the organizations' preparedness for the future in terms of technological assets and competences [36]. It evaluates the long-term benefits offered by a project portfolio (i.e. creation of new markets and development of new technologies and capabilities) [33]. Portfolio balance concerns the equilibrium of risks, long- and short-term opportunities, and the steady utilization of resources within the project portfolio's execution [10, 27]. Synergy exploitation represents the added value that emerges from dedicated portfolio management in addition to the single projects' contribution through the capitalization of interdependencies and avoiding redundancies [23, 28, 37]. The fifth dimension, average economic project success, corresponds to the assertion that project portfolio management is an antecedent to project 
success [26, 27]. Average economic project success is measured by the achievement of objectives related to target costs, target revenues, customer satisfaction, and profitability. Hence, it focuses on project effectiveness instead of efficiency [38].

In accordance with these five dimensions of success, the interpretation of project portfolio management extends beyond the initial evaluation, prioritization, and selection of projects, and also incorporates the allocation of resources, concurrent re-evaluation of projects, and exploitation of the project portfolio [22, 39, 40]. Previous research analyzing the project portfolio manager's tasks defines four phases of project portfolio management [28]:

The first phase (portfolio structuring) refers to the composition of a target portfolio that contributes the highest value to the organization and is aligned with the corporate strategy. It comprises the evaluation, prioritization, and selection of projects [35]. The main challenge for portfolio structuring is to ensure the accuracy, validity, and comparability of information to support the evaluation and prioritization of project proposals [40]. Often, required information for decision making is flawed: benefits are overstated, costs are underestimated (e.g. through strategic misrepresentation optimism bias), and exaggerated urgency undermines the selection process by falsely suggesting high priority for resource allocation [13, 14, 15, 41, 42].

The second phase (resource allocation) concerns the cross-project planning and allocation of resources that reflect the projects' priorities and aim for optimal utilization of available resources (in particular human resources). In theory, this phase is very closely linked to the portfolio structuring phase. However, in practice resource allocation is often not aligned with the strategic priorities of the portfolio [43]. Due to the competition for scarce resources, conflicts may arise between projects and between projects and the line organization [44]. Engwall and Jerbrandt blame resource allocation failure on: 1) the dysfunction of classical management accounting systems for multi-project environments, which leads to contradictory goals by treating projects as resource users and line management as resource providers, and 2) the opportunistic behavior of project managers in overstating project priority [39]. 
The third phase (portfolio steering) comprises the ongoing project portfolio management tasks for the coordination and control of the project portfolio [8]. Research shows that the organization's ability to make decisions proactively about a project's continued existence or termination is an antecedent to portfolio success in terms of strategic fit [45]. These decision capabilities, as well as the overall project portfolio management performance, depend heavily on the information available to management. Steering of the portfolio requires that information about the projects and the external environment is considered. Deviations from project plans and changing external conditions can both potentially cause the loss of expected project benefits; these conditions may require re-evaluation and re-prioritization of these projects. However, ongoing control mechanisms to ensure the validity of a project's business case are rarely implemented in practice [41].

The fourth phase (organizational learning and portfolio exploitation) addresses activities that are located at the end of the project's life-cycle [28]. The importance of post-project evaluation and reviews is highlighted from a learning perspective. The underlying rationale is that post-project evaluation and the development of lessons learned can help to advance an organization's project management practice and contribute to the success of subsequent projects [46]. Portfolio exploitation refers to the transition of project outputs to the customer and the transformation of these outputs to outcomes and benefits. In particular, at the interface between the project and the customer's line organization, essential knowledge and competence may be lost [47]. A challenge in this fourth phase is that most companies have not successfully implemented post-project review processes [48], and that after project closure, there can be a lack of motivation to invest further effort [49]. Without such review and learning processes, valuable assets are lost at the organizational and portfolio level. Thus, the benefits realization management literature highlights the importance of clearly defined roles acting at this interface [2]. 
With the project portfolio management phases and the respective goals and challenges in mind, we describe the role of the project business case and its application from a project portfolio perspective (through business case control) in the following section.

\section{Business Case Control}

We use the term 'business case control' (BCC) to describe the use of project business cases from a project portfolio-level control perspective. The scope of control comprises more than merely monitoring: it encompasses planning, monitoring, reporting, taking necessary corrective action, and re-planning [50]. Taking a process perspective, we identify three main stages for the application of project business cases: the initial selection of project investment proposals, the monitoring and re-prioritization of ongoing projects, and eventually the appraisal of the business performance and business case validation. Since business case control refers to the project portfolio level, the concept does not comprise the content or quality of the individual project business cases which are generally managed at the project level. Accordingly, we propose that three elements constitute business case control: 1) the use of business cases for evaluating and prioritizing project proposals (business case existence), 2) the continuous monitoring of the validity of ongoing projects (business case monitoring), and 3) the tracking of the business case in terms of benefits realized after project completion (business case tracking). These three elements can be assigned to the four project portfolio phases and are sequential in application, in that each element requires a certain proficiency of the previous one. Below we describe each of the three elements of business case control and its contribution to project portfolio success in more detail.

Business case existence refers to application of business cases within the portfolio structuring and resource allocation phases, where it encompasses not only the presence of a business case, but also its quality in terms of accuracy, validity, comprehensiveness, and comparability. To ensure high-quality business cases, project portfolio managers must establish common 
rules and guidelines for the business case design (often through standard templates or forms) and perform rigorous and independent business case reviews [2, 4, 21].

Business case monitoring is an activity that accompanies the project from initiation until closure and is processed in the portfolio steering phase. It refers to the continuous validation of a project's business case, considering changing conditions that may stem from the project itself (i.e. scope changes or plan deviations) or from the project's environment (e.g. new technologies and competitors or changing major stakeholder interests) that aggravate or invalidate the original business case. Gardiner and Steward emphasize the importance of continuous monitoring, stating that most companies discover deviations and changing conditions too late to react [41]. In the same vein, Dvir and Lechler suggest that initial planning quality cannot compensate for how changes during a project's life-cycle can affect the project's success [51]. Hence, the ongoing monitoring of the business case enables management to make proactive decisions about the portfolio of projects; early access to information will widen options and may involve adjusting project scope or urgency - or cancelling projects to make way for alternative opportunities.

Business case tracking refers to the evaluation of project results regarding the realization of the business case. As the added value described in the business case usually does not refer to the direct project output, but rather to the outcomes and benefits resulting from the output, business case tracking takes place after project completion. While the contribution of postproject reviews to organizational learning is widely acknowledged [46, 48, 52, 53], we propose an additional benefit of business case tracking. The very existence of post-project reviews affects the behavior of those responsible for the business case, increases their efforts, and may prevent them from overstating benefits or understating efforts in the business case [54].

These definitions show how each of the three elements of business case control supports project portfolio management, addressing challenges in each of the four phases. In this way, 
our definitions support prior research that has claimed that project portfolio controlling should be applied throughout project processes - beyond initial project evaluation and selection [7, $8]$. 
TABLE II

Business Case Control along the Project Portfolio Management Phases

\begin{tabular}{|c|c|c|c|}
\hline Phase & Challenges & Role of BCC & Contribution \\
\hline Structuring & $\begin{array}{l}\text { Project business cases } \\
\text { suffer from flawed } \\
\text { information, } \\
\text { incomparable statements, } \\
\text { and inaccurate estimates. }\end{array}$ & $\begin{array}{l}\text { Existence and } \\
\text { monitoring: Ensuring } \\
\text { existence of the business } \\
\text { case and scrutinizing } \\
\text { reviews across all project } \\
\text { proposals. }\end{array}$ & $\begin{array}{l}\text { Increased portfolio value by informed } \\
\text { investment decisions (based on } \\
\text { improved validity and accuracy of } \\
\text { business cases) } \\
\text { Related success dimensions: } \\
\text { - Avg. economic project success } \\
\text { - Portfolio balance }\end{array}$ \\
\hline $\begin{array}{l}\text { Resource } \\
\text { allocation }\end{array}$ & $\begin{array}{l}\text { Optimal resource } \\
\text { allocation is aggravated } \\
\text { by a lack of transparency } \\
\text { regarding the relative } \\
\text { priority and urgency of } \\
\text { projects. }\end{array}$ & $\begin{array}{l}\text { Existence and } \\
\text { Monitoring: } \\
\text { Establishing common } \\
\text { requirements and quality } \\
\text { standards for business } \\
\text { cases aiming for } \\
\text { comparability }\end{array}$ & $\begin{array}{l}\text { Improved resource allocation in } \\
\text { accordance to priorities (based on } \\
\text { transparent and comparable project } \\
\text { benefits) } \\
\text { Related success dimensions: } \\
\text { - Synergy exploitation } \\
\text { - Strategy implementation }\end{array}$ \\
\hline Steering & $\begin{array}{l}\text { Go/no-go decision can be } \\
\text { flawed due to unseen } \\
\text { changes of environ- } \\
\text { mental developments and } \\
\text { late detection of } \\
\text { (creeping) deviations } \\
\text { from project plans. }\end{array}$ & $\begin{array}{l}\text { Monitoring: Ongoing } \\
\text { monitoring of the } \\
\text { validity of business cases } \\
\text { in regards to changing } \\
\text { internal and external } \\
\text { conditions }\end{array}$ & $\begin{array}{l}\text { Enhanced responsiveness and } \\
\text { capability of early detection of } \\
\text { unprofitable investments } \\
\text { Related success dimensions: } \\
\text { - Avg. economic project success } \\
\text { - Synergy exploitation } \\
\text { - Strategy implementation }\end{array}$ \\
\hline $\begin{array}{l}\text { Learning and } \\
\text { exploitation }\end{array}$ & $\begin{array}{l}\text { Organizational learning } \\
\text { lacks motivation and } \\
\text { sufficient effort, and } \\
\text { output exploitation } \\
\text { suffers from the } \\
\text { transition between } \\
\text { project and customer } \\
\text { organization. }\end{array}$ & $\begin{array}{l}\text { Tracking: Post-project } \\
\text { tracking of business case } \\
\text { realization }\end{array}$ & $\begin{array}{l}\text { Increased business case planning } \\
\text { capabilities through organizational } \\
\text { learning and improved effort for } \\
\text { project exploitation through increased } \\
\text { transparency. } \\
\text { Related success dimensions: } \\
\text { - Avg. economic project success } \\
\text { - Future preparedness }\end{array}$ \\
\hline
\end{tabular}

Business case control contributes to project portfolio success by increasing transparency and information accuracy, enabling timely response to changing conditions, and fostering organizational learning. Table II summarizes how business case control contributes to project portfolio success by addressing some of the main challenges for project portfolio management. For each of the phases outlined in the previous section, Table II highlights the role of the three $\mathrm{BCC}$ elements and the contribution of $\mathrm{BCC}$ to project portfolio management. Hence, we argue that the application of business case control is beneficial for project portfolio success and propose our first hypothesis.

H1: Business case control is positively related to project portfolio success. 


\section{Enablers of Business Case Control}

We have hypothesized that the process of business case control contributes to project portfolio success. This hypothesis is only part of the picture; in this section we explore potential complementary managerial practices that leverage the performance effect of business case control. While the process is a necessary condition and forms the framework for successful management practices, the actors are of pivotal importance when it comes to implementation $[28,55]$. Furthermore, a lack of commitment on the part of the actors, and unclear roles and responsibilities, are known as major problem areas in multi-project management $[56,57]$.

Since benefits are generally realized after project completion [58], benefits management requires an overarching responsibility that outlives the project [2]. The benefits management literature offers a wide range of role definitions, such as the benefit owner, the senior responsible owner, the business sponsor, the executive sponsor, the benefit facilitator, the business change manager, the project executive, the senior project user, or the project funder $[2,4,50,59,60,61]$. While the benefit owner is the actual beneficiary of a project (usually the organization procuring the project), some scholars argue that further roles are necessary to 'harvest' the promised benefits [2, 59]. On the other side, the UK Office of Government Commerce (OGC) stated that a separate tier of management is not required, but that the roles and responsibilities of the actors related to project, program, and portfolio management need to be extended [20]. These additional roles are proposed to address an inability and lack of motivation by the project customers' organizations to get involved in projects early, due to their permanent workload [2]. However, assigning such responsibilities is often difficult in practice [62].

Zwikael and Smyrk underpin the importance of the benefit owner and the line manager in the utilization of project outputs, whereas the responsibility of the project manager ends with delivery of these outputs. However, they acknowledge that project managers may be the best candidates to support the realization phase due to their "intimate familiarity with the outputs 
that have been implemented" [60: 264]. Following this rationale, the assignment of accountability for business case realization likewise refers to the customer, the line management, and the project management.

Previous research provides evidence that management support for the hand-over of project outputs to the customer increases performance [63], while a lack of accountability has been associated with overly optimistic estimates and flawed business cases [15]. Furthermore, professionals in dedicated benefits realization roles will be appraised by the success of the business case realization [60], and are likely to have a keen interest in, and challenge, the information provided by business case control.

In summary, prior research suggests that the assignment of accountability (i.e. an explicit assignment with clearly defined targets for business case realization) plays an important role in the context of business case realization. This applies especially to the benefit owners, namely the project customer and its line organization. We argue that accountability for business case realization facilitates the effect of business case control on project portfolio success by reducing optimism bias and increasing the relevance and utilization of the information provided by business case control. In this way, business case accountability fosters the relationship between business case control and project portfolio success.

H2: The relationship between business case control and project portfolio success is stronger the better accountability for business case realization is defined (positive moderation).

However, role assignment is a 'toothless tiger' if it lacks corresponding stimuli to assure that respective actors perform as intended. Monetary incentive systems have become increasingly popular in recent years [64]. Eisenhardt draws upon principal-agent theory to describe how incentive systems are designed to align the interest of the agents with goals of the principal [65]. However, the idea of incentive systems impacting motivation is controversial $[66,67]$. Critics argue that intrinsic motivation, which is important to produce a desired behavior, may 
be undermined by extrinsic incentives, an issue also known as crowding-out effect [64, 66, $68]$.

In project management research the use of incentives or disincentives within project contracting is generally supported and has been the subject of several studies [69, 70]. However, in the context of business case control, the drafting of contracts is rather a precondition and may be an input factor for evaluating a business case. Thus, the present study does not focus on contract design but rather on individual incentives for the actors involved in the realization of a business case.

Tosi et al. provide evidence that incentive alignment is more effective than monitoring in ensuring that agents act in the interest of the owner [71]. Although their study cannot confirm the interaction effect between monitoring and incentives, they highlight the relevance of this effect as described by Milgrom and Roberts [72]. Accordingly, accurate monitoring is a prerequisite to align the actors' behavior with the owner's interest by setting the respective incentives.

In the context of this study the owner (principal) is the organization that invests in the project proposals. The interest of the organization is not the output of each individual project, but rather the value added by the whole portfolio [58]. Only if an organization is transparent about the value added by the project portfolio do incentives affect management behavior and contribute to project portfolio success. The information provided by business case control provides this transparency and forms the basis for an incentive system that aligns the behavior of the relevant actors (agents) to the owner's interest. As projects are temporary organizations that recruit their resources from the permanent line organizations $[39,55]$ and compete for resources with the other projects of the portfolio [7], not only the project manager, but also the line managers and the project portfolio manager, are highly relevant actors. Therefore, we propose that for these relevant actors incentive systems based on project portfolio success are complementary to business case control in their effect on portfolio success. 
H3: The relationship between business case control and project portfolio success is stronger the more the incentives for the relevant actors are aligned to project portfolio success (positive moderation).

\section{E. Contingencies of Business Case Control}

While the previously discussed enablers of business case control are part of the management system itself, contingencies represent circumstances that are outside the management's sphere of influence and that moderate the effect of business case control on performance. Project portfolio management research refers to complexity as the main contingency $[10,33]$. In accordance with previous research we understand a project portfolio as a system in which complexity is defined by the number of elements (i.e. projects), referred to as portfolio size, the number of relationships between these elements in terms of interdependency, and the system's dynamics caused by external turbulence $[10,33,73]$.

Researchers argue that the relevance of project portfolio management and the formalization of portfolio processes increases with portfolio size and with stronger interdependency between projects in terms of required resources and knowledge, and inter-related project outcomes [10, 26]. One of the main outcomes of business case control is the provision of transparency. The larger a project portfolio and the stronger the interdependencies, the more difficult it is to maintain transparency without dedicated control functions. Conversely, in small project portfolios the effort to implement and maintain business case control may not justify the value it contributes. Hence, we argue that the contribution of business case control to project portfolio success increases with the number of projects included in the portfolio and the interdependencies between these projects. External turbulence affects business cases in two ways. First, a business case is required to make assumptions regarding future environmental conditions (i.e. exchange rates, behavior of competitors, and market and technological developments). Greater turbulence increases the uncertainty about future developments, 
which is generally reflected as risk in the business case. The resulting increased complexity of the business case creates the need for even more rigorous business case reviews. Second, unforeseeable and rapidly changing environmental conditions may affect the validity and longevity of a business case. Close monitoring is required to detect and respond to these effects in a timely manner. Accordingly, we propose that the relevance of business case control is higher when external turbulence is high.

H4: The relationship between business case control and project portfolio success is stronger a) with increasing number of projects, b) with higher interdependency between projects, and c) in more turbulent environments (positive moderation).

Figure 1 summarizes the conceptual model. In addition to positioning each hypothesis within a single model, the figure shows the control mechanisms tested in this research. Since the management of project portfolios represents a wide range of activities, the research is designed to examine the differences between business case control and other aspects of portfolio management that have been shown to be important for portfolio success: the formalization of portfolio management and the maturity of single project management $[8,10$, 26]. Both concepts are distinct from business case control and have been shown to be important for portfolio success [10, 26].

The formalization of portfolio management is "the degree to which formal rules and procedures, such as the existence of formal review meetings, exist for the project portfolio management process" [10: 601]. The degree of formalization has been repeatedly shown to be highly correlated with portfolio success in studies that measure formalization as a general framework of rules and procedures within which the portfolio is governed, and the degree of consistency and compliance with the rules and procedures $[10,74]$. In contrast, our concept of business case control specifically focuses on the control of project business cases across the portfolio. It is a content-specific managerial task rather than a formal procedure. Thus, the application of business case control does not necessarily imply a highly formalized portfolio 
management or vice-versa. We highlight this distinction and reveal the specific contribution of business case control by controlling for formalization of portfolio management [10].

Business case control is located at the portfolio management level in our model; however, portfolio management success is also influenced by the maturity of single project management activities. Previous research shows that single project management maturity is an important prerequisite for portfolio management $[10,26]$. In the same way, the quality and accuracy of business cases stem from planning and monitoring skills at the single project level. These project management skills are basic requirements for developing valid and comprehensive business cases. Developing a business case at the project level and managing business cases at the portfolio level both foster the quality of business cases, yet they are different managerial tasks. To highlight this distinction and the particular relevance of business case control we control for single project management maturity. It comprises the standardization of project management processes and the actual project management capabilities in terms of planning, controlling, and decision-making [10, 12]. Lastly, we also control for the size of the portfolio in terms of overall budget.

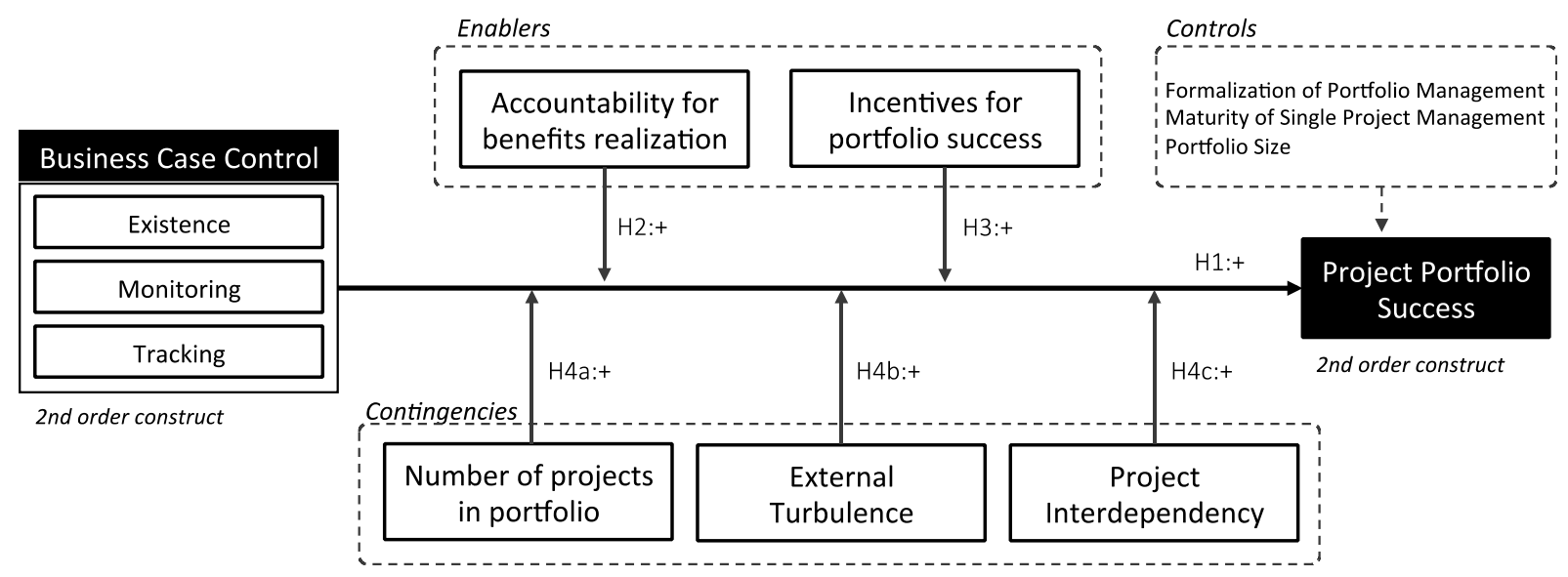

Fig. 1. Conceptual model. 


\section{METHOD}

\section{A. Sample}

We used a cross-industry sample of medium-sized to large firms in Germany to test the hypotheses. The object of analysis is the project portfolio of a firm (or business unit in case of large firms). For each project portfolio we contacted two key informants - a decision maker and a coordinator. Decision maker informants had decision authority over the portfolio in deciding on initiation, termination, or reprioritization of projects (e.g. CEO, CIO, head of R\&D). Coordinator informants had a good overview of the project landscape and were in charge of actively managing the portfolio (e.g. portfolio manager, department manager, or head of PMO). This two-informant approach allows the integration of information from different perspectives and hierarchies. More importantly, it avoids common method bias [75], because decision maker informants assessed the dependent variable and coordinator informants assessed the independent variables.

We first contacted firms by mail, explaining the study and inviting participation by potential coordinator informants or their superiors. Afterwards we contacted them again by phone. All registered informants received by e-mail a personal letter explaining the multi-informant design and the questionnaire with an introduction describing the terms and definitions. To increase the response rate, follow-up phone calls were conducted and reminder e-mails were sent. We received 189 decision maker questionnaires and 195 coordinator questionnaires from 200 firms, resulting in 184 matched dyads with data from both types of informants. One observation had to be removed from analysis due to missing data. After the study each firm received an individual report of the findings and the overall study results were presented, discussed, and validated at a conference with about 90 participants. The 183 firms representing the final sample came from diverse industries (26\% automotive, $18 \%$ electronics/IT, $16 \%$ finance, $11 \%$ construction and utility, $8 \%$ health care, $7 \%$ logistics, $5 \%$ pharmaceuticals/chemicals, $9 \%$ others). The sample showed a reasonable spread of firm size: 
fewer than 500 employees (32\% of firms), 500-2,000 (29\%), or more than 2,000 (39\%). Portfolio budget ranged from less than $€ 20$ million (3\% of portfolios), to $€ 20-100$ million (39\%), to higher than $€ 100$ million (24\%). The median number of projects in a portfolio was 50.

\section{B. Measurement}

We used multi-item scales for the constructs, anchored from 1, "strongly disagree", to 7 , "strongly agree". Since no existing scales were available for most of the variables, we operationalized these scales following previous conceptual work: all scales were pretested with 12 representatives from academia and industry to assure face validity of constructs, improve item wording, and remove ambiguity. We validated the scales using principal components factor analysis (PCFA) and confirmatory factor analysis (CFA) [76]. PCFA tests for unidimensionality of each scale by checking whether all items load onto a single factor. Cronbach's Alpha was used to assess scale reliability with acceptable values larger than .7. The CFA confirmed the measurement model and the second-order structure of business case control and project portfolio success. We followed the guidelines of $\mathrm{Hu}$ and Bentler [77] to evaluate structural equation models (i.e. Comparative Fit Index (CFI) of .95 for good and of .90 for acceptable fit; Standardized Root Mean Squared Residual (SRMSR) below .08 and Root Mean Squared Error of Approximation (RMSEA) below .06 for good fit). All item wordings are shown in the Appendix.

Dependent variable. Project portfolio success was measured as a five-dimensional secondorder construct using dimensions and their items from existing literature [12, 32, 33]: strategy implementation (4 items), future preparedness ( 3 items), portfolio balance (3 items), average economic project success (4 items), and synergy exploitation (3 items). PCFA showed that all items loaded highly on their respective dimensions with no cross-loadings above 0.30 . The CFA confirmed the second-order structure in that all dimensions loaded highly on the overall 
construct (smallest loading .66) and the model fit was acceptable $\left(\chi^{2}[114, p<.00]=214.40\right.$; RMSEA $=.071 ;$ SRMR $=.068 ; \mathrm{CFI}=.94)$. The coordinator informant also assessed project portfolio success. Although we did not use the information for hypothesis testing, we could use it for further validation of the scale. The coordinator assessment resulted in the same factor structure with similar loadings and was highly correlated with the decision maker assessment $(\mathrm{r}=.57, \mathrm{p}<.00)$, which gave strong confidence in the validity of our measure.

Independent variable. We developed measures for business case control based on conceptual literature $[2,17,18,20,62]$ along three elements: business case existence (5 items), business case monitoring ( 4 items), and business case tracking (5 items). PCFA showed high crossloadings in one item, which was consequently eliminated.

Moderator Variables. Accountability was measured using 5 items [2, 47]. One item was eliminated as a result of the PCFA. Incentives for portfolio success was measured using 4 items based on Tosi et al. [71] and Milgrom and Roberts [72]. Environmental turbulence included 3 technology and 3 market turbulence items taken from Sethi and Iqbal [73]. Project interdependencies was measured by 3 items from Teller et al. [10]. Finally, number of projects was measured as the natural logarithm of the number of projects contained in the portfolio. The CFA on all latent independent and moderator variables had an acceptable fit $\left(\chi^{2}[361, \mathrm{p}<.00]=566.64 ; \mathrm{RMSEA}=.056 ; \mathrm{SRMR}=.060 ; \mathrm{CFI}=.93\right)$ and confirmed the second-order structure of business case control (all second-order factor loadings were above .78). The three elements of business case control were highly correlated, as the high secondorder loadings show, yet they were empirically distinct.

Control variables. We further introduced into our model three variables that might affect project portfolio success and should be controlled for. Single project management maturity was measured with 6 items from Teller et al. [10]. On the level of the portfolio we controlled for the formalization of the PPM process that we measured with 4 items Teller et al. [10]. We finally controlled for the budget of the portfolio measured as the natural logarithm of the 
budget in millions of Euro. Correlations and descriptives for all variables are shown in Table

III. Because business case control correlated not only with project portfolio success but also with accountability and maturity of single project management, we checked for any collinearity that may affect the analysis. The highest variance inflation factor was 1.68 and the highest condition index as 2.31 , both well under the suggested thresholds for collinearity of 10 and 30 , respectively.

TABLE III

CORRELATIONS AND DESCRIPTIVES

\begin{tabular}{|c|c|c|c|c|c|c|c|c|c|c|c|c|}
\hline & Variable & $\mathbf{M}$ & SD & (1) & (2) & (3) & (4) & (5) & (6) & (7) & (8) & (9) \\
\hline (1) & Project Portfolio Success & 4.58 & .80 & 1 & & & & & & & & \\
\hline (2) & Portfolio Budget (ln) & 74.08 & 182.4 & -.07 & 1 & & & & & & & \\
\hline (3) & $\begin{array}{l}\text { Maturity of Single Project } \\
\text { Management }\end{array}$ & 5.28 & 1.09 & .34 & -.08 & 1 & & & & & & \\
\hline (4) & $\begin{array}{l}\text { Formalization of } \\
\text { Portfolio Management }\end{array}$ & 4.71 & 1.74 & .32 & -.01 & .33 & 1 & & & & & \\
\hline (5) & Number of Projects (ln) & 4.03 & 1.21 & .03 & .02 & .03 & .21 & 1 & & & & \\
\hline (6) & Project Interdependency & 3.95 & 1.16 & -.05 & -.08 & .00 & .03 & -.02 & 1 & & & \\
\hline (7) & External Turbulence & 4.01 & 1.07 & .11 & -.01 & .03 & .02 & .08 & .19 & 1 & & \\
\hline (8) & Accountability & 4.49 & 1.41 & .16 & .03 & .42 & .10 & .05 & -.02 & -.03 & 1 & \\
\hline (9) & Incentives & 2.22 & 1.26 & .12 & .08 & .09 & .11 & .19 & -.04 & .04 & .12 & 1 \\
\hline (10) & Business Case Control & 4.20 & 1.28 & .30 & .12 & .43 & .24 & .09 & .09 & -.02 & .54 & .20 \\
\hline
\end{tabular}

\section{RESULTS}

We used ordinary least squares regression in order to test the hypotheses. The results are displayed in Table IV. The first model contains only the direct effects of all control and moderator variables. Only the maturity of single project management and the formalization of portfolio management are significantly related to project portfolio success $(b=.17, p<.01$, and $\mathrm{b}=.11, \mathrm{p}<.01$, respectively). Model 2 introduces business case control, which has a positive and significant coefficient $(b=.14, \mathrm{p}<.01)$. The model explains $22 \%$ of variance in portfolio success, which is very satisfactory considering that it is not inflated by common method bias. 
The basic hypothesis that business case control is positively associated with project portfolio success is therefore supported by the data. Models 3-7 test the moderation hypotheses using the procedures proposed by Aiken et al. [78]. In each model we introduce the product-term between the centered independent variable and the centered moderator variable. If the coefficient is significant and the explained variance of the model significantly increases in comparison with Model 2, the moderation hypothesis is supported. In Model 3 the interaction effect with accountability for benefits realization is positive and significant $(b=.06, p<.05)$, which supports Hypothesis 2. Incentives for project portfolio success also show a positive interaction effect $(b=.10, p<.01)$ in Model 4, which is in support of Hypothesis 3. Models 5-7 show that with increasing number of projects $(b=.10, \mathrm{p}<.01)$, with increasing project interdependency $(b=.08, p<.05)$, and under higher external turbulence $(b=.12, p<.01)$, the relationship between business case control and project portfolio success becomes stronger, supporting Hypothesis 4. Overall, all hypotheses find support in our data.

For the visualization of the moderation effects we used marginal plots instead of simple slopes, as they show the strength and significance of the effect of business case control on project portfolio success for each value of the moderator [79]. The solid lines in figures 2 and 3 represent the overall effect over the whole range of moderator values. The dashed lines represent $95 \%$ confidence intervals. Figure 2 shows that business case control is positively and significantly related to project portfolio success only if accountability for benefits realization is above 4, which is still lower than the mean in this sample (4.5). A similar effect can be observed regarding the incentives for portfolio success. When incentives are higher than approximately 2 (slightly lower than the sample mean of 2.22), the effect of business case control becomes significantly positive. Figure 3 shows the effect for the number of projects (ln). Above a value of 4 (i.e. roughly 50 projects) the benefits of business case control become significantly positive. Concerning external turbulence, Figure 3 informs that above the average turbulence of roughly 4 the effects are positive and significant. Notably, none of 
the moderators lead to significantly negative effects of business case control. Table V summarizes the findings related to each hypothesis.

TABLE IV

\section{REGRESSION RESULTS}

\begin{tabular}{|c|c|c|c|c|c|c|c|}
\hline & \multicolumn{7}{|c|}{ Project Portfolio Success } \\
\hline & (1) & $(2)$ & $(3)$ & $(4)$ & $(5)$ & (6) & (7) \\
\hline \multicolumn{8}{|l|}{ Controls } \\
\hline Portfolio Budget (ln) & .00 & .00 & .00 & .00 & .00 & .00 & .00 \\
\hline Maturity of Single Project Management & $.17^{* *}$ & $.13^{*}$ & $.13^{*}$ & $.14^{*}$ & $.14^{*}$ & $.15^{*}$ & $.16^{* *}$ \\
\hline Formalization of Portfolio Management & $.11^{* *}$ & $.10^{* *}$ & $.09^{* *}$ & $.10^{* *}$ & $.09^{*}$ & $.11^{* *}$ & $.10^{* *}$ \\
\hline \multicolumn{8}{|l|}{ Moderators } \\
\hline Accountability for Benefits Realization & .02 & -.04 & -.02 & -.04 & -.05 & -.03 & -.06 \\
\hline Number of Projects (ln) & -.03 & -.03 & -.05 & -.04 & -.04 & -.03 & -.03 \\
\hline Project Interdependency & -.07 & -.09 & -.08 & -.06 & -.08 & $-.10^{*}$ & -.08 \\
\hline External Turbulence & .09 & .10 & .09 & .10 & $.10^{*}$ & $.11^{*}$ & $.13^{*}$ \\
\hline Incentives for Portfolio Success & .04 & .02 & .04 & .01 & .02 & .04 & .02 \\
\hline \multicolumn{8}{|l|}{ Independent Variable } \\
\hline H1: Business Case Control (BCC) & & $.14^{* *}$ & $.15^{* *}$ & $.16^{* *}$ & $.14^{* *}$ & $.14^{* *}$ & $.14^{* *}$ \\
\hline \multicolumn{8}{|l|}{ Interaction Effects } \\
\hline $\mathrm{H} 2$ : BCC x Accountability & & & $.06^{*}$ & & & & \\
\hline H3: BCC x Incentives & & & & $.10^{* *}$ & & & \\
\hline H4a: BCC x Number of Projects & & & & & $.10^{* *}$ & & \\
\hline H4b: BCC x Project Interdependency & & & & & & $.08^{*}$ & \\
\hline H4c: BCC x Turbulence & & & & & & & $.12^{* *}$ \\
\hline Constant & $4.58^{* *}$ & $4.59^{* *}$ & $4.53^{* *}$ & $4.55^{* *}$ & $4.57^{* *}$ & $4.57^{* *}$ & $4.58^{* *}$ \\
\hline $\mathrm{R}^{2}$ & .19 & .22 & .24 & .25 & .25 & .24 & .25 \\
\hline $\mathrm{R}^{2}$ (adjusted) & .15 & .18 & .19 & .21 & .21 & .21 & .21 \\
\hline Delta $R^{2}$ & & $.03^{*}$ & $.02^{*}$ & $.03^{*}$ & $.04^{* *}$ & $.02^{*}$ & $.04^{* *}$ \\
\hline $\mathrm{F}$ & $4.94^{* *}$ & $5.32^{* *}$ & $5.32^{* *}$ & $5.83^{* *}$ & $5.85^{* *}$ & $5.48^{* *}$ & $6.23^{* *}$ \\
\hline
\end{tabular}

Hierarchical OLS regression; $n=183$; mean-centered variables; unstandardized regression coefficients are reported; * $\mathrm{p}<.05 ; * * \mathrm{p}<.01$ (two-sided); BCC=Business Case Control.

TABLE V

SUMMARY OF RESULTS

\begin{tabular}{ll}
\hline No. Hypothesis & Result \\
\hline H1: Business case control is positively related to project portfolio success & supported \\
\hline H2: The relationship between business case control and project portfolio success is stronger the & supported \\
better accountability for business case realization is defined (positive moderation). & \\
\hline H3: The relationship between business case control and project portfolio success is stronger the & supported \\
more the incentives for the relevant actors are aligned to project portfolio success (positive & \\
moderation). & supported \\
H4: The relationship between business case control and project portfolio success is stronger .... \\
$\begin{array}{l}\text { a) with increasing number of projects, } \\
\text { b) with higher interdependency between projects, and } \\
\text { c) in more turbulent environments (positive moderation). }\end{array}$ \\
\hline
\end{tabular}



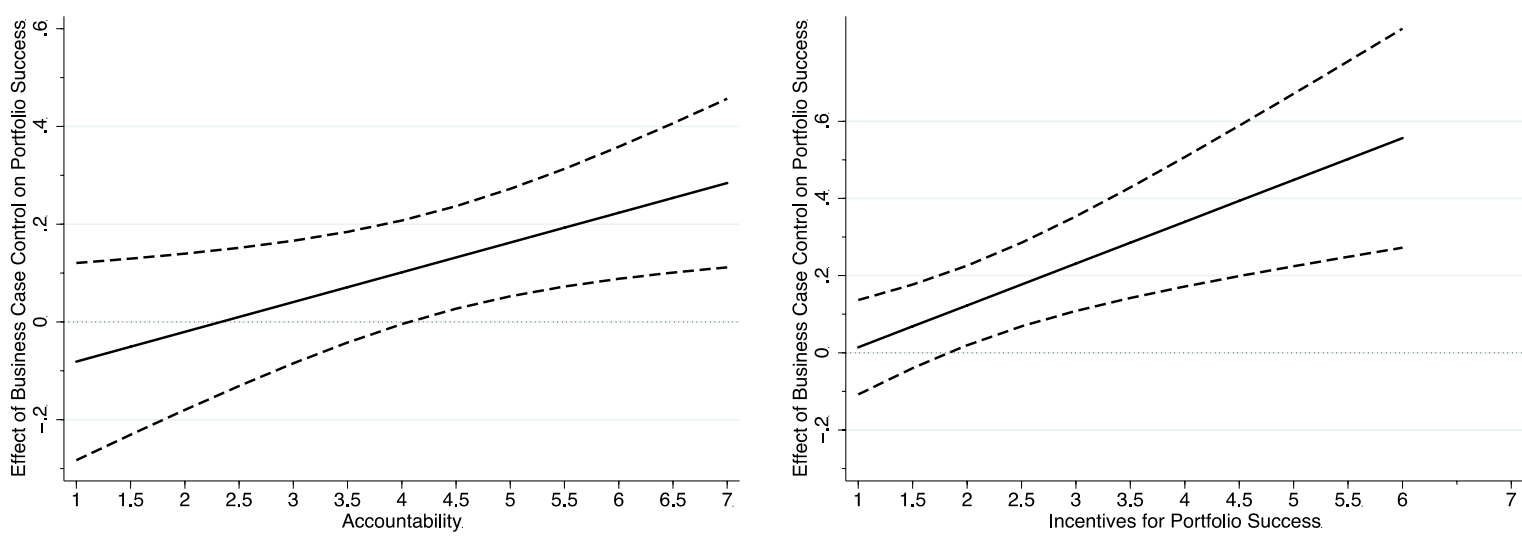

Fig. 2. Marginal effects of Business Case Control depending on accountability and incentives (the dashed lines represent 95 per cent confidence intervals).
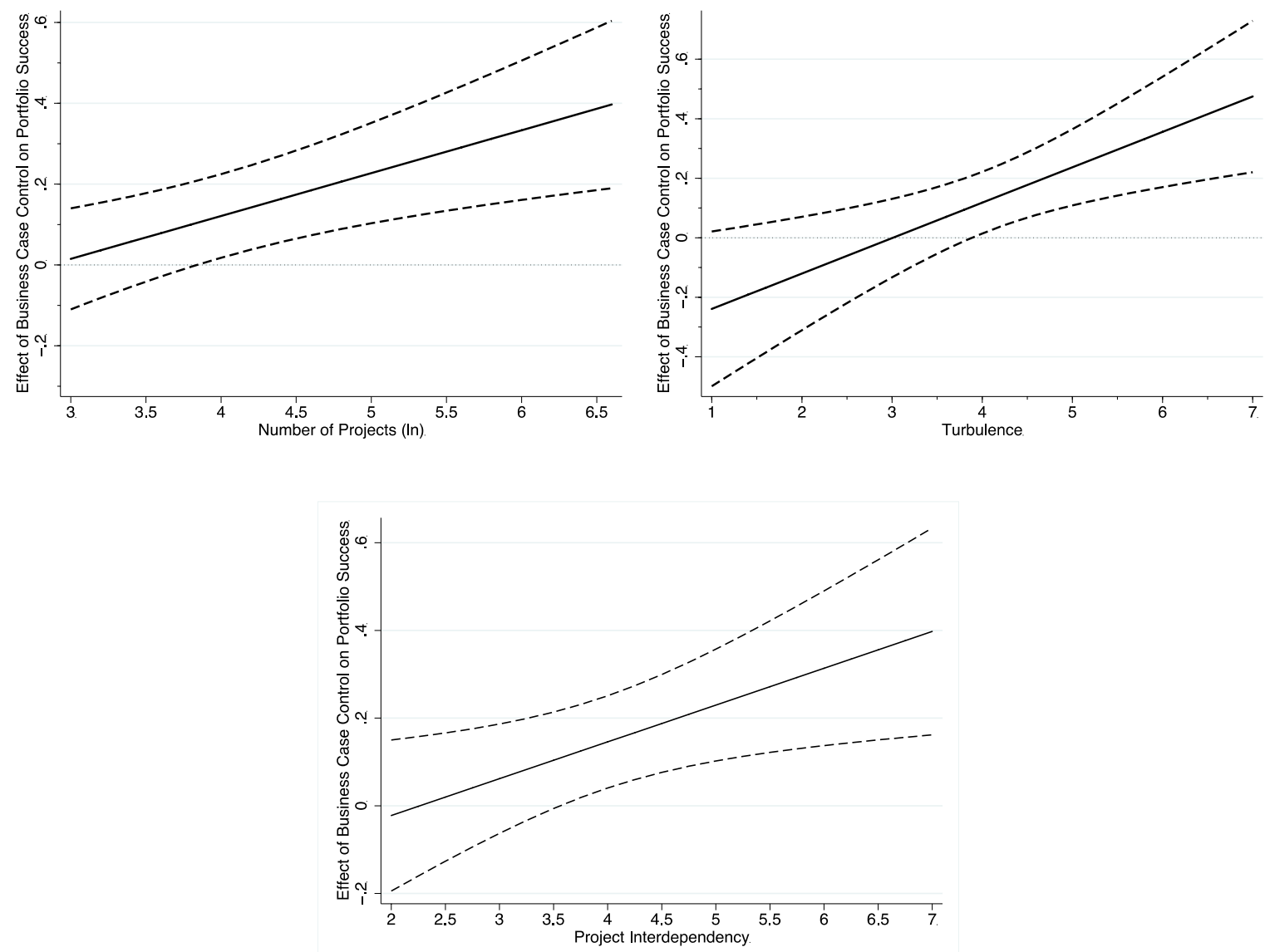

Fig. 3. Marginal effects of Business Case Control depending on number of projects, project interdependency, and external turbulence.

\section{DISCUSSION}

\section{A. Implications for Research}

This study examines the role of business case control within project portfolio management by developing a conceptual model based on the literature from project, project portfolio, and 
benefits realization management and empirically testing the proposed relationships. By doing so, we make three primary contributions to research.

First, this study introduces the construct of business case control and shows its predictive relevance for project portfolio success. We conceptualize business case control as consisting of three elements: existence, monitoring, and tracking. Empirically validating the measurement of this second-order construct by confirmatory factor analysis, we find that the three elements are highly correlated yet distinct. Our empirical results show a significant variance in the application of business control practices across organizations. Furthermore, we establish the overall construct for business case control as distinct from other related constructs in project portfolio management research, such as single project management maturity and the formalization of project portfolio management. We provide the first largescale empirical test of the application of business case control as a method of benefits management at the project portfolio level. Altogether, this study provides evidence for the effectiveness of business case control with respect to project portfolio success and illustrates the breadth of application from portfolio structuring through to portfolio exploitation and benefit realization.

The results suggest that a project business case can be utilized for more than the investment appraisal that informs the funding decision-making: the merits of business case control also stem from the monitoring and post-project validation. These insights contribute to research by showing the effectiveness of practices beyond the scope of most project portfolio management studies (which tend to be limited to the selection of projects and allocation of resources and don't reflect the full breadth of PPM). While previous research on post-project evaluation concentrates primarily on the learning perspective $[46,48,80,81,82]$, our study of business case tracking highlights additional merits of a post-project review and provides a perspective to address problems of optimism bias and strategic misrepresentation [13, 14]. 
Future research can build upon these insights by analyzing the impact of business case tracking on these issues in more detail.

This study introduces business case control as a controlling task at the project portfolio management level and analyzes its relevance without scrutinizing the actual content of a project business case. However, previous studies have repeatedly demonstrated the importance of the content of the business case. For example, research on IT investments suggests that business cases that solely focus on financial criteria can lead to a range of drawbacks (e.g. encouraging 'creative' calculations or understating organizational costs) [4], and research from product development emphasizes the importance of portfolio balance for portfolio success and highlights the range of considerations (such as levels of risk and innovativeness) that business cases need to include [83]. Future research could analyze the content and quality of a project business case as an antecedent of project and project portfolio success. While the present study shows the relevance of business cases and the corresponding governance systems from a portfolio perspective, future research could complement our findings from a single project perspective. Such a perspective can reveal the requirements and challenges of distinct project types. For example, the effect of using business cases may vary between projects with internal and external customers.

Future research building on our first main contribution might also explore the impact of business case control on other dependent variables, such as the innovativeness of the portfolio or the motivation of the affected stakeholders. Such research might help to uncover the overall effects of applying business case control in project portfolio management. For example, there may be negative effects, such as the hidden cost of control or the erosion of intrinsic motivation $[64,66,68,84]$.

The second main contribution of this research is the identification of core enablers of business case control. Our results show that the control process is positively moderated by the existence of defined roles, which assign accountability and suggest relevant incentives for 
business case realization. Although prior studies have suggested that there might be an interaction effect between monitoring and incentives, they were not able to confirm this effect $[54,71]$. Our findings confirm the moderating effects and reveal the conditions under which business case control works. We find that without accountability and incentives for portfolio success, business case control is less effective. However, prior research provides no consensus and describes a range of roles related to benefits management $[2,4,57,59]$. Our findings may motivate future researchers to explore the actual design of such roles. It might be fruitful to analyze the interplay between the main actors (i.e. project customers, project managers, portfolio managers, and line managers) and how accountability and incentives affect their collaboration. Such efforts could also challenge traditional perceptions of human resource management and organizational control $[85,86]$. For example, entrepreneurial traits may be revealed that contradict project managers' perception of their traditional role, which focuses only on adhering to budget, time, and quality.

Third and finally, this research contributes to contingency research in project management by identifying appropriate management practices depending on the context $[10,87]$. We find that business case control contributed more strongly to project portfolio success in larger project portfolios, in more interdependent portfolios, and in more turbulent environments. These findings may open avenues for further research that builds upon organizational control theory $[88,89]$. The theory identifies distinct types of control, which align organizational members' behavior with organizational goals, and proposes that the effectiveness of each type of control depends upon the environment. Following organizational control theory, outcome control is the means of choice in complex environments and when environmental changes are difficult to predict [90]. Business case control is an outcome control method, while the traditional project management control measures of time, cost, and quality are types of process control, which are more suitable for predictable and stable environments according to organizational control theory [91]. Hence, the findings of this study align with insights from organizational 
control theory in the context of project portfolio management and could lead the way for further research contributing to both streams of literature.

\section{B. Limitations}

The results of this study should be evaluated keeping the following limitations in mind. First, the analysis relies on cross-sectional data and is unable to show project evolution over time. We posit that applying business case control in project portfolio management will increase portfolio success and we show a positive association. However, we cannot rule out the possibility that the causation is reverse, that is, that firms invest more in business case control because they have been successful in the past (e.g. due to more resources at their disposal). Only a longitudinal study could corroborate the suggested causality.

Second, the study does not explore the mechanisms through which the performance gains from business case control come to pass. Future research might explore how the consideration of business cases affects decision-making processes at the project portfolio level in more detail. Overemphasis on single-project business cases risks distracting management attention away from pursuing an optimal overall portfolio (selecting the individually best projects does not guarantee the best portfolio). For example, future studies might explore how the consideration of business cases relates to the identification and management of synergies or portfolio-related risks. Furthermore, applying business case control may have positive and negative effects that work simultaneously. For example, too many formal controls may limit creativity and might strain innovation, which could outweigh the positive effects in some portfolio environments such as $R \& D$ project portfolios. The current study opens the black box between business case control and portfolio success and offers an initial vantage point for further investigations of possible mediation effects. 


\section{Implications for Management}

This study provides a comprehensive description of business case control that can be used by project portfolio managers to benchmark their current practice. Furthermore, this study provides directions for implementing a business case control process. We highlight avenues for improving and extending project portfolio management practices by revealing the importance of business case monitoring and tracking throughout project phases. Both the assigning of accountability for the business case and the setting of incentives for project portfolio success facilitate the effect of business case control; managers should consider these jointly. However, we also reveal internal and external contingencies that suggest that business case control is not always an appropriate approach for a project portfolio. In smaller portfolios and for portfolios in stable external environments business case control is less beneficial.

Our research demonstrates that business case control can be a valuable activity that contributes to project portfolio success. Managers can draw upon this study in order to evaluate the usefulness of business case control in their context, and to guide them in the design and implementation of business case control practices.

\section{REFERENCES}

[1] R. Atkinson, "Project management: Cost, time and quality, two best guesses and a phenomenon, its time to accept other success criteria," International Journal of Project Management, vol. 17, pp. 337-342, 1999.

[2] T. Cooke-Davies, "Managing Benefits," in Gower Handbook of Project Management, R. Turner, Ed., 4 ed Burlington: Gower Publishing Limited, 2007, pp. 245-259.

[3] S. Jenner, Transforming government and public services: Realising benefits through project portfolio management: Gower Publishing Company, 2010.

[4] J. Ward, E. Daniel, and J. Peppard, "Building Better Business Cases for IT Investments," MIS Quarterly Executive, vol. 7, pp. 1-15, 2008.

[5] IPMA, IPMA Competence Baseline (ICB) Version 3.0. Nijkerk: International Project Management Association, 2006.

[6] R. G. Cooper, S. J. Edgett, and E. J. Kleinschmidt, "Portfolio management for new product development: Results of an industry practices study," $R \& D$ Management, vol. 31, pp. 361-380, 2001.

[7] N. P. Archer and F. Ghasemzadeh, "An integrated framework for project portfolio selection," International Journal of Project Management, vol. 17, pp. 207-216, 1999.

[8] R. Müller, M. Martinsuo, and T. Blomquist, "Project Portfolio Control and Portfolio Management Performance in Different Contexts," Project Management Journal, vol. 39, pp. 28-42, 2008. 
[9] C. Wooje and M. J. Shaw, "Portfolio Selection Model for Enhancing Information Technology Synergy," IEEE Transactions on Engineering Management, vol. 60, pp. 739-749, 2013.

[10] J. Teller, B. N. Unger, A. Kock, and H. G. Gemünden, "Formalization of project portfolio management: The moderating role of project portfolio complexity," International Journal of Project Management, vol. 30, pp. 596-607, 2012.

[11] P. Dietrich and P. Lehtonen, "Successful management of strategic intentions through multiple projects-Reflections from empirical study," International Journal of Project Management, vol. 23, pp. 386-391, 2005.

[12] D. Jonas, A. Kock, and H. G. Gemünden, "Predicting project portfolio success by measuring management quality - a longitudinal study," IEEE Transactions on Engineering Management, vol. 60, pp. 215-226, 2013.

[13] B. Flyvbjerg, "Curbing optimism bias and strategic misrepresentation in planning: Reference class forecasting in practice," European Planning Studies, vol. 16, pp. 3-21, 2008.

[14] P. E. D. Love, D. J. Edwards, and Z. Irani, "Moving Beyond Optimism Bias and Strategic Misrepresentation: An Explanation for Social Infrastructure Project Cost Overruns," IEEE Transactions on Engineering Management, vol. 59, pp. 560-571, 2012.

[15] S. Jenner, Realising Benefits from Government ICT Investment - A fool's errand? , 1 ed. Reading, UK: Academic Publishing International Ltd, 2009.

[16] R. Breese, "Benefits realisation management: Panacea or false dawn?," International Journal of Project Management, vol. 30, pp. 341-351, 2012.

[17] PMI, The Standard for Program Management, 3 ed. Pensylvania: Project Management Institute, Inc., 2013.

[18] PMI, The Standard for Portfolio Management, 3 ed. Pensylvania: Project Management Institute, Inc., 2013.

[19] PMI, A Guide to the Project Management Body of Knowledge: PMBOK Guide: Project Management Institute, Incorporated, 2013.

[20] OGC, Management of Value, 1 ed. Norwich: The Stationery Office, 2010.

[21] GAPPS, A Framework for Performance Based Competency Standards for Program Managers. Sydney: Global Alliance for Project Performance Standards, 2011.

[22] B. S. Blichfeldt and P. Eskerod, "Project portfolio management - There's more to it than what management enacts," International Journal of Project Management, vol. 26, pp. 357-365, 2008.

[23] S. Meskendahl, "The influence of business strategy on project portfolio management and its success - A conceptual framework," International Journal of Project Management, vol. 28, pp. 807-817, 2010.

[24] B. N. Unger, J. Rank, and H. G. Gemünden, "Corporate Innovation Culture and Dimensions of Project Portfolio Success: The Moderating Role of National Culture," Project Management Journal, vol. 45, pp. 38-57, 2014.

[25] J. Teller, A. Kock, and H. G. Gemünden, "Risk Management in Project Portfolios Is More Than Managing Project Risks: A Contingency Perspective on Risk Management," Project Management Journal, vol. 45, pp. 67-80, 2014.

[26] M. Martinsuo and P. Lehtonen, "Role of single-project management in achieving portfolio management efficiency," International Journal of Project Management, vol. 25, pp. 56-65, 2007.

[27] C. P. Killen, R. A. Hunt, and E. J. Kleinschmidt, "Project portfolio management for product innovation," International Journal of Quality \& Reliability Management, vol. 25, pp. 24-38, 2008.

[28] D. Jonas, "Empowering project portfolio managers: How management involvement impacts project portfolio management performance," International Journal of Project Management, vol. 28, pp. 818-831, 2010.

[29] R. G. Cooper, S. J. Edgett, and E. J. Kleinschmidt, Portfolio management for new products. Cambridge: Perseus Publishing, 2002.

[30] S. J. Edgett, "Portfolio Management for Product Innovation," in The PDMA Handbook of New Product Development, K. B. Kahn, Ed., 3 ed: Wiley, 2012, pp. 154-166.

[31] M. Martinsuo and C. P. Killen, "Value Management in Project Portfolios: Identifying and Assessing Strategic Value," Project Management Journal, vol. 45, pp. 56-70, 2014. 
[32] J. Teller and A. Kock, "An empirical investigation on how portfolio risk management influences project portfolio success," International Journal of Project Management, vol. 31, pp. 817-829, 2013.

[33] M. Voss and A. Kock, "Impact of relationship value on project portfolio success - Investigating the moderating effects of portfolio characteristics and external turbulence," International Journal of Project Management, vol. 31, pp. 847-861, 2013.

[34] A. Kock, W. Heising, and H. G. Gemünden, "How Ideation Portfolio Management Influences Front-End Success: Ideation Portfolio Management," Journal of Product Innovation Management, 2015.

[35] P. W. G. Morris and A. Jamieson, "Moving from Corporate Strategy to Project Strategy," Project Management Journal, vol. 36, pp. 5-18, 2005.

[36] A. J. Shenhar, D. Dvir, O. Levy, and A. C. Maltz, "Project Success: A Multidimensional Strategic Concept," Long Range Planning, vol. 34, pp. 699-725, 2001.

[37] P. Patanakul, "Key Drivers of Effectiveness in Managing a Group of Multiple Projects," IEEE Transactions on Engineering Management, vol. 60, pp. 4-17, 2013.

[38] T. G. Lechler and D. Dvir, "An alternative taxonomy of project management structures: Linking project management structures and project success," IEEE Transactions on Engineering Management, vol. 57, pp. 198-210, 2010.

[39] M. Engwall and A. Jerbrant, "The resource allocation syndrome: The prime challenge of multiproject management?," International Journal of Project Management, vol. 21, pp. 403-409, 2003.

[40] M. H. A. Hendriks, B. Voeten, and L. H. Kroep, "Human resource allocation in a multi-project R\&D environment: Resource capacity allocation and project portfolio planning in practice," International Journal of Project Management, vol. 17, pp. 181-188, 1999.

[41] P. D. Gardiner and K. Stewart, "Revisiting the golden triangle of cost, time and quality: the role of NPV in project control, success and failure," International Journal of Project Management, vol. 18, pp. 251-256, 2000.

[42] W. G. Meyer, "The Effect of Optimism Bias on the Decision to Terminate Failing Projects," Project Management Journal, vol. 45, pp. 7-20, 2014.

[43] S. E. Fricke and A. Shenbar, "Managing multiple engineering projects in a manufacturing support environment," IEEE Transactions on Engineering Management, vol. 47, pp. 258-268, 2000.

[44] K. P. Grant and J. S. Pennypacker, "Project management maturity: an assessment of project management capabilities among and between selected industries," IEEE Transactions on Engineering Management, vol. 53, pp. 59-68, 2006.

[45] B. N. Unger, A. Kock, H. G. Gemünden, and D. Jonas, "Enforcing strategic fit of project portfolios by project termination: An empirical study on senior management involvement," International Journal of Project Management, vol. 30, pp. 675-685, 2012.

[46] M. von Zedtwitz, "Organizational learning through post-project reviews in $\mathrm{R} \& \mathrm{D}, " R \& D$ Management, vol. 32, pp. 255-268, 2002.

[47] M. Winter and T. Szczepanek, Images of Projects. Burlington: Gower Publishing Company, 2009.

[48] F. T. Anbari, E. G. Carayannis, and R. J. Voetsch, "Post-project reviews as a key project management competence," Technovation, vol. 28, pp. 633-643, 2008.

[49] J. S. Busby, "An assessment of post-project reviews," Project Management Journal, vol. 30, pp. 23-29, 1999.

[50] P. W. G. Morris, Reconstructing project management. Somerset, NJ, USA: Wiley, 2013.

[51] D. Dvir and T. Lechler, "Plans are nothing, changing plans is everything: the impact of changes on project success," Research Policy, vol. 33, pp. 1-15, 2004.

[52] C. Ashurst, N. F. Doherty, and J. Peppard, "Improving the impact of IT development projects: the benefits realization capability model," European Journal of Information Systems, vol. 17, pp. 352-370, 2008.

[53] C. Ashurst and J. Hodges, "Exploring business transformation: The challenges of developing a benefits realization capability," Journal of Change Management, vol. 10, pp. 217-237, 2010.

[54] R. C. Mahaney and A. L. Lederer, "The role of monitoring and shirking in information systems project management," International Journal of Project Management, vol. 28, pp. 14-25, 2010. 
[55] C. Beringer, D. Jonas, and A. Kock, "Behavior of internal stakeholders in project portfolio management and its impact on success," International Journal of Project Management, vol. 31, pp. 830-846, 2013.

[56] S. Elonen and K. A. Artto, "Problems in managing internal development projects in multi-project environments," International Journal of Project Management, vol. 21, pp. 395-402, 2003.

[57] R. R. Nelson, "IT Project Management: Infamous Failures, Classic Mistakes, and Best Practices," MIS Quarterly Executive, vol. 6, 2007.

[58] O. Zwikael and J. Smyrk, "A General Framework for Gauging the Performance of Initiatives to Enhance Organizational Value," British Journal of Management, vol. 23, pp. S6-S22, 2012.

[59] G. Bradley, Benefit Realisation Management: A Practical Guide to Achieving Benefits Through Change: Ashgate Publishing, Limited, 2010.

[60] O. Zwikael and J. Smyrk, Project management for the creation of organisational value. London et al.: Springer, 2011.

[61] OGC, Managing successful programmes. Norwich, UK: The Stationery Office, 2011.

[62] OGC, Management of Portfolios. Norwich, UK: The Stationery Office, 2011.

[63] D. Dvir, "Transferring projects to their final users: The effect of planning and preparations for commissioning on project success," International Journal of Project Management, vol. 23, pp. 257-265, 2005.

[64] U. Gneezy, S. Meier, and P. Rey-Biel, "When and why Incentives (don't) work to modify behavior," The Journal of Economic Perspectives, vol. 25, pp. 191-209, 2011.

[65] K. M. Eisenhardt, "Agency theory: An assessment and review," Academy of Management Review, vol. 14, pp. 57-74, 1989.

[66] B. S. Frey and R. Jegen, "Motivation Crowding Theory," Journal of Economic Surveys, vol. 15, pp. 589-611, 2001.

[67] T. K. Abdel-Hamid, K. Sengupta, and M. J. Hardebeck, "The effect of reward structures on allocating shared staff resources among interdependent software projects: an experimental investigation," IEEE Transactions on Engineering Management, vol. 41, pp. 115-125, 1994.

[68] E. L. Deci, R. Koestner, and R. M. Ryan, "A meta-analytic review of experiments examining the effects of extrinsic rewards on intrinsic motivation," Psychological Bulletin, vol. 125, pp. 627$668,1999$.

[69] A. A. Bubshait, "Incentive/disincentive contracts and its effects on industrial projects," International Journal of Project Management, vol. 21, pp. 63-70, 2003.

[70] X. Meng and B. Gallagher, "The impact of incentive mechanisms on project performance," International Journal of Project Management, vol. 30, pp. 352-362, 2012.

[71] H. Tosi, J. P. Katz, and L. R. Gomez-Mejia, "Disaggregating the agency contract: the effects of monitoring, incentive alignment, and term in office on agent decision making," Academy of Management Journal, vol. 40, pp. 584-602, 1997.

[72] P. R. Milgrom and J. Roberts, Economics, organization and management vol. 7: Prentice-Hall Englewood Cliffs, NJ, 1992.

[73] R. Sethi and Z. Iqbal, "Stage-Gate Controls, Learning Failure, and Adverse Effect on Novel New Products," Journal of Marketing, vol. 72, pp. 118-134, 2008.

[74] C. P. Killen, R. A. Hunt, and E. J. Kleinschmidt, "Project portfolio management for product innovation," The International Journal of Quality \& Reliability Management, vol. 25, pp. 24-38, 2008.

[75] P. M. Podsakoff, S. B. MacKenzie, J.-Y. Lee, and N. P. Podsakoff, "Common method biases in behavioral research: a critical review of the literature and recommended remedies," Journal of applied psychology, vol. 88, p. 879, 2003.

[76] S. L. Ahire and S. Devaraj, "An empirical comparison of statistical construct validation approaches," IEEE Transactions on Engineering Management, vol. 48, pp. 319-329, 2001.

[77] L.-t. Hu and P. M. Bentler, "Fit Indices in Covariance Structure Modeling: Sensitivity to Underparameterized Model Misspecification," PSYCHOLOGICAL METHODS, vol. 3, pp. 424453, 1998.

[78] L. S. Aiken, S. G. West, and R. R. Reno, Multiple regression: testing and interpreting interactions: Sage Publications, 1991. 
[79] T. Brambor, W. R. Clark, and M. Golder, "Understanding interaction models: Improving empirical analyses," Political analysis, vol. 14, pp. 63-82, 2006.

[80] M. von Zedtwitz, "Post-project reviews in R\&D," Research Technology Management, vol. 46, pp. 43-49, 2003.

[81] A. Prencipe and F. Tell, "Inter-project learning: processes and outcomes of knowledge codification in project-based firms," Research Policy, vol. 30, pp. 1373-1394, 2001.

[82] M. Schindler and M. J. Eppler, "Harvesting project knowledge: a review of project learning methods and success factors," International Journal of Project Management, vol. 21, pp. 219$228,2003$.

[83] R. G. Cooper, S. J. Edgett, and E. J. Kleinschmidt, "New product portfolio management: Practices and performance," Journal of Product Innovation Management, vol. 16, pp. 333-351, 1999.

[84] A. Falk and M. Kosfeld, "The Hidden Costs of Control," American Economic Review, vol. 96, pp. 1611-1630, 2006.

[85] K. Bredin and J. Söderlund, "HRM and project intensification in R\&D- based companies: a study of Volvo Car Corporation and AstraZeneca," R\&d Management, vol. 36, pp. 467-485, 2006.

[86] K. Bredin and J. Söderlund, Human resource management in project-based organizations: The HR quadriad framework. New York: Palgrave Macmillan, 2011.

[87] D. Howell, C. Windahl, and R. Seidel, "A project contingency framework based on uncertainty and its consequences," International Journal of Project Management, vol. 28, pp. 256-264, 2010.

[88] W. G. Ouchi, "A conceptual framework for the design of organizational control mechanisms," Management science, vol. 25, pp. 833-848, 1979.

[89] W. G. Ouchi, "The relationship between organizational structure and organizational control," Administrative Science Quarterly, pp. 95-113, 1977.

[90] K. L. Turner and M. V. Makhija, "The role of organizational controls in managing knowledge," Academy of Management Review, vol. 31, pp. 197-217, 2006.

[91] C. Schultz, S. Salomo, U. Brentani, and E. J. Kleinschmidt, "How Formal Control Influences Decision-Making Clarity and Innovation Performance," Journal of Product Innovation Management, vol. 30, pp. 430-447, 2013.

\section{APPENDIX - MEASUREMENT}

Project Portfolio Success ( $\mathbf{2}^{\text {nd }}$ order construct) Strategy Implementation ( $\alpha=.85$, second order loading $\lambda=.78$ )

The project portfolio is consistently aligned with the future of the company. The corporate strategy is implemented ideally through our project portfolio. Resource allocation to projects reflects our strategic objectives. The implementation of the strategy is considered a great success in the organization. Future Preparedness ( $\alpha=.88, \lambda=.66$ ) We sufficiently develop new technologies and/or competences in our projects. With our projects we are a step ahead of our competition with new products, technologies, or services. The projects enable us to shape the future of our industry. Portfolio Balance $(\alpha=.85, \lambda=.68)$ There is a good balance in our project portfolio... ....between new and old areas of application. ...between new and existing technologies. $\ldots$ of project risks. Average economic project success $(\alpha=.88, \lambda=.69)$ Please assess the average success of completed projects: Our products/project results achieve the target costs defined in the project. Our products/project results achieve the planned market goals (e.g., market share). Our products/project results achieve the planned profitability goals (e.g., ROI). Our products achieve the planned amortization period. Synergy Exploitation ( $\alpha=.88, \lambda=.70$ ) During the project execution, development synergies (e.g. shared use of modules, platforms, technologies etc.) between projects are rigorously exploited. After project completion, exploitation synergies (e.g. shared marketing/sales channels, infrastructure, etc.) between projects are rigorously exploited. We hardly ever have double work or redundant development. 
Business Case Control (2nd order construct) Existence $(\alpha=.85, \lambda=.80)$ All projects must have a business case in order to enter the selection process. "Must-Projects" also have to prove a business case. We closely examine the business case within portfolio structuring. The business case is examined by experts from different departments. Overall, business cases are elaborated very well and conscientiously (discarded). Monitoring ( $\alpha=$ $.88, \lambda=.91)$ We check the business case for validity at specified points in time or events in the course of the project and adjust if necessary. Once a project is approved a review of the objectives is rare (reversed). We check on a regular basis for each business case whether the necessary conditions are still valid. When the project scope or course has changed the implications on the business case is always checked. Tracking $(\alpha=.88, \lambda=.78)$ Once a project is completed, no further consideration takes place (reversed). At project completion, we not only check the adherence to costs, time and specifications of the project, but also the fulfillment of the business case. Even within a certain period after project completion it is regularly checked if the originally targeted business case could be realized. We systematically analyze the results of the review of the business case. The subsequent analysis of business cases provides us with valuable insights.

Incentives for portfolio success $(\alpha=$.75) Project managers receive a special bonus, which is based on the success of the project portfolio. Portfolio coordinators receive a special bonus, which is based on the success of the project portfolio. Line managers receive a special bonus, which is based on the success of the project portfolio.

Accountability $(\alpha=0.88)$ For the take-over and exploitation of project results clear responsibilities and roles are defined (discarded). Even after project completion responsibilities for the realization of the business case are clearly defined. The role of the project user including certain duties is clearly defined. Project users have clearly defined targets regarding the exploitation of the project results. The line management on the project user's side have clearly defined targets regarding the exploitation of the project results.

Project Interdependency ( $\alpha=0.81$ ) A high degree of alignment between our projects is required with respect to the scopes. Scope changes of individual projects inevitably impact on the execution of other projects. Often projects can only be continued if the results of other projects are available.

Environmental Turbulence $(\alpha=0.84)$ The technology in our industry is changing rapidly. There are frequent technological breakthroughs in our industry. Technological changes provide big opportunities in our industry. In our industry, it is difficult to predict how customers' needs and requirements will evolve. In our kind of business, customers' product preferences change quite a bit over time. In our industry, it is difficult to forecast competitive actions.

PPM Formalization $(\alpha=0.93)$ Essential project decisions are made within clearly defined portfolio meetings. Our project portfolio management process is divided in clearly defined phases. Our process for project portfolio management is clearly specified. Overall we execute our project portfolio management process very well structured.

Single PM Maturity $(\alpha=0.82)$ For each project a detailed project plan is developed and updated until project completion. For all projects a complete and timely recording of working hours of the project staff takes place. A standardized process model is established and practiced by all project participants. Project managers are very familiar with our project management standards and are very well qualified for their tasks. Each project has a steering committee and defined escalation paths. Overall we perform a professional single project management. 